\title{
State of blood pressure control in adult type 2 diabetic patients with chronic kidney disease and hypertension: experience from a tertiary care centre of Bangladesh
}

\author{
Khan MSH ${ }^{\mathrm{a}}$, CHY UK ${ }^{\mathrm{b}}$, Islam MR ${ }^{\mathrm{c}}$, Alam ${ }^{\mathrm{d}}$, Habib R ${ }^{\mathrm{e}}$, Latif ZA
}

\begin{abstract}
Background: Well controlled blood pressure (BP) is associated with decreased risk of kidney disease progression, cardiovascular events and death. Patients with chronic kidney disease (CKD) are frequently seen to have low rates of BP control. This study aimed to find out the proportion of adult type 2 diabetic CKD patients with hypertension achieving the goal of target blood pressure.
\end{abstract}

Methods: This cross-sectional study included 105 hypertensive subjects having type 2 diabetes and CKD at the outpatient department of Nephrology, BIRDEM General Hospital in Dhaka, Bangladesh from May to August, 2012.

Results: The mean age was 55.6 years and maximum numbers of patients were in the age group of 39-66 years. Among 105 subjects, 52.3\% were male and rest $47.7 \%$ were female. The mean duration of diabetes, CKD and hypertension were $6.73( \pm 3.22), 3.12( \pm 2.47)$ and $3.1( \pm 1.77)$ years respectively. The study revealed that ---ischemic heart disease (30.5\%), dyslipidemia (56.1\%) and stroke (13.3\%) were associated comorbidity along with diabetes and CKD. Mean estimated glomerular filtration rate was $52.19 \mathrm{ml} / \mathrm{min}$. Mean serum creatinine level was $3.4 \mathrm{mg} /$ $d l$. It was observed that majority (49.5\%) of the study subjects were prescribed at least two drugs to control hypertension. Three anti-hypertensive medications were given in 35.2\% subjects. Among 105 study subjects, $25.7 \%$ were found to have high systolic blood pressure and $8.8 \%$ high diastolic blood pressure. It was observed that only $40 \%$ subjects achieved target systolic blood pressure and $68.6 \%$ reached the target diastolic pressure for CKD with diabetes. In correlation analysis, it was observed that both systolic and diastolic blood pressure was significantly correlated with age of the subject, duration diabetes and duration of HTN.

Conclusion: From the present study it was seen that both the target systolic and diastolic blood pressure were correlated with numbers of medications used for controlling hypertension but only diastolic blood pressure control was significantly correlated with number of medication used in this present study.

Key words: type 2 diabetes mellitus, hypertension, chronic kidney disease.

(BIRDEM Med J 2021; 11(3): 212-217)

\section{Author information}

a. Mohammad Sakhawat Hossen Khan, Registrar, Department of Neurology, BIRDEM General Hospital, Dhaka, Bangladesh.

b. Umme Kulsum Chy, Junior Consultant, Department of Critical Care Medicine, United Hospital Limited, Dhaka, Bangladesh.

c. Md. Rashedul Islam, Assistant Professor, Department of Neurology, BIRDEM General Hospital, Dhaka, Bangladesh.

d. Dilruba Alam, Registrar, Department of Neurology, BIRDEM General Hospital, Dhaka, Bangladesh.

e. Rumana Habib, Associate Professor, Department of Neurology, BIRDEM General Hospital, Dhaka, Bangladesh.

f. Zafar Ahmed Latif, Professor of Endocrinology, BIRDEM General Hospital, Dhaka, Bangladesh.

Address of correspondence: Mohammad Sakhawat Hossen Khan, Registrar, Department of Neurology, BIRDEM General Hospital, Dhaka, Bangladesh. Email: rubelszmc@gmail.com

Received: April 3, 2021

Revision received: July 17, 2021

Accepted: July 31, 2021

\section{INTRODUCTION}

Diabetes mellitus (DM) is a major public health problem throughout the world and is one of the leading causes of death in most countries. ${ }^{1}$ In 2019 , the International Diabetes Federation(IDF) estimated that 465 million (9.3\%) people worldwide had diabetes and by 2045 , the number may rise to 700 million (10.9\%). ${ }^{2}$ Bangladesh is facing a continuous growth in the prevalence of diabetes. According to the International Centre for Diarrhoeal Disease Research in Bangladesh in 2015, 7.1 million people had diabetes, 3.7 million cases were undiagnosed and about 129000 deaths were attributed to the disease. ${ }^{3}$ The prevalence of diabetes in Bangladesh, based on published studies, ranges from $2.21 \%$ to $35 \% ., 5$ 
Chronic kidney disease (CKD) is another leading cause of death and disability. In 1990, CKD was the 27th leading cause of death which rose up and became 18th leading cause of death in $2010 .{ }^{6}$ A systematic review, conducted in 2015 reported that, 109.9 million people from highincome countries had CKD whereas the burden was 387.5 million in lower-middle income countries. ${ }^{7} \mathrm{CKD}$ poses a huge burden on the health system of South Asian countries. This is not unusual considering the high prevalence of diabetes and hypertension in this region. ${ }^{8,9}$

Hypertension has been estimated to be responsible for $13 \%$ of global deaths. ${ }^{10}$ With the projection of a $30 \%$ increase in worldwide prevalence of this condition by the year 2025 and for its pivotal role in the rising global burden of disease and disability, hypertension has become one of the most challenging concerns for world public health. Persistent untreated hypertension can also lead to kidney failure. Studies estimate that threequarters of the world's hypertensive population reside in low- and middle-income countries and the prevalence of hypertension is higher in low- and middle-income countries $(31.5 \%)$ than in highincome countries (28.5\%). ${ }^{11,12}$ Bangladesh is one of those low- and middle-income countries that experiencing an epidemiological transition from communicable to noncommunicable diseases. ${ }^{13}$

Hypertension is both a cause and effect of CKD and contributes to its progression. ${ }^{14}$ AseGFR declines, the incidence and severity of hypertension increase. Additionally, hypertension and CKD are both independent risk factors for cardiovascular disease (CVD). When both exist together the risks of CVD morbidity and mortality are substantially increased. ${ }^{15}$ Importantly, from a therapeutic perspective, lowering BP can slow eGFR decline, delay progression to ESRD, and reduce the incidence of CVD in this patient group. ${ }^{16}$

Twelve million of adults aged 25 years or older in Bangladesh suffer from hypertension with higher prevalence in the urban rather than in the rural population.6 Earlier reports also showed that $12-15 \%$ of Bangladeshis aged 20 years or older had hypertension. ${ }^{17}$ Low awareness is common in populations in lowincome settings including Bangladesh. ${ }^{18}$ Research has shown that greater awareness is associated with higher adherence to antihypertensive treatments and BP control. ${ }^{19}$ Despite a huge disease burden attributable to hypertension and very high rate of unawareness, it is largely an unrecognized and under-researched public health problem in Bangladesh. This study was carried out with the aim to find out the proportion of adult type 2 diabetic and CKD patients with hypertension achieving the goal of target blood pressure.

\section{METHODS}

This cross-sectional study was done in the Department of Nephrology, Bangladesh Institute of Research and Rehabilitation in Diabetes, Endocrine and Metabolic Disorders (BIRDEM) General Hospital from May to August, 2012. Adult diabetic patients with CKD (stage $1-5$ ) and hypertension were included in this study. CKD patients on renal replacement therapy, patient of acute kidney injury (AKI) and AKI on CKD were excluded. Blood pressure was measured in sitting position using mercury manometer with Riva-Rocci cuff. Demographic information was recorded and substantiated by means of inspection of medical records. Information included was the subject's age, gender, medical history, clinical history of CKD, followed by conduction of the study.

\section{Ethical consideration}

Prior to the commencement of this study, the research protocol was approved by ethical review committee of Bangladesh Diabetic Association. The objectives of this study along with risks and benefit were fully explained to the subjects in easily understandable local language and then informed written consent was taken from each patient. It was assured that all information and records would be kept confidential and the procedure would be helpful for both the physician and the patient in making rational approach of the case management.

\section{Statistical analysis}

Data were filled into MS Excel 2010 and analyzed by SPSS 20 version. For descriptive analysis frequency, percentage, mean, median, standard deviation were calculated and presented in tabular form whereas for inferential statistics independent t-test was applied as per need to find out the difference between groups. We considered values as statistically significant at a $95 \%$ confidence interval if $\mathrm{p}<0.05$. 


\section{RESULTS}

Total patients were 105 with 52 (47.6\%) males and mean age was 55.7 (range 39 - 66) years. Mean duration of diabetes, CKD and hypertension were $6.73( \pm 3.22), 3.12$ $( \pm 2.47)$ and $3.1( \pm 1.77)$ years respectively (Table I). Other comorbidities are shown in Table II. Among the diabetic complications, $34.3 \%$ had peripheral vascular disease, $80 \%$ had diabetic neuropathy and $94.3 \%$ had diabetic retinopathy. Mean eGFR (eGFR by CG formula) was 52.19 $\mathrm{ml} / \mathrm{min}$. Serum creatinine and serum urea levels are shown in Table III.

\section{Table I Duration of disease in the study subjects} $(\mathrm{N}=105)$

\begin{tabular}{lcc}
\hline Duration of diabetes (years) & Number & Percentage \\
\hline$\leq 5$ & 47 & 44.7 \\
$>5$ & 58 & 55.2 \\
Mean \pm SD & 6.7 & \pm 03.22 \\
Range(minimum-maximum) & & $3-10$ \\
Duration of CKD (years) & & \\
$\leq 5$ & 76 & 72.4 \\
$>5$ & 29 & 27.6 \\
Mean \pm SD & 3.12 & \pm 2.47 \\
Range(minimum-maximum) & & $1-5$ \\
Duration of hypertension (years) & & \\
$\leq 5$ & 82 & 78.1 \\
$>5$ & 23 & 21.9 \\
Mean \pm SD & 3.10 & \pm 1.77 \\
Range(Minimum-maximum) & & $2-6$ \\
\hline
\end{tabular}

Table II Co-morbid conditions of the study subjects $(\mathrm{N}=105)$

\begin{tabular}{lcc}
\hline Co-morbid conditions & Number & Percentage \\
\hline Ischemic heart disease & 32 & 30.5 \\
Dyslipidaemia & 59 & 56.2 \\
Stroke & 14 & 13.3 \\
\hline
\end{tabular}

*Multiple responses were elicited
Table III Renal functional profile of the study subjects $(\mathrm{N}=105)$

\begin{tabular}{lc}
\hline Variable & $($ mean $\pm \mathrm{SD})$ \\
\hline eGFR $(\mathrm{ml} / \mathrm{min})$ & $52.19 \pm 27.13$ \\
Serum creatinine $(\mathrm{mg} / \mathrm{dl})$ & $3.4 \pm 2.3$ \\
Serum urea $(\mathrm{mg} / \mathrm{dl})$ & $88.3 \pm 29.3$ \\
\hline
\end{tabular}

Ten $(9.5 \%)$ patients were receiving one antihypertensive drug, 52 (49.5\%) were prescribed two medications, 37 $(35.2 \%)$ were give three drugs only $6(5.7 \%)$ subjects were having more than three drugs. Only $40 \%$ subjects achieved target systolic blood pressure level and 68.6\% reached the recommended diastolic pressure level for CKD with diabetes (Table IV). Correlation between achieving target blood pressure level and some selected variables is shown in Table V and VI.

\begin{tabular}{|c|c|c|}
\hline $\begin{array}{l}\text { Systolic blood pressure } \\
\text { (mm of } \mathrm{Hg} \text { ) }\end{array}$ & Number & Percentage \\
\hline$\leq 130$ & 42 & 40.0 \\
\hline 131-139 & 36 & 34.3 \\
\hline$\leq 140$ & 27 & 25.7 \\
\hline $\begin{array}{l}\text { Diastolic blood pressure } \\
(\mathrm{mm} \text { of } \mathrm{Hg})\end{array}$ & Number & Percentage \\
\hline$\leq 80$ & 72 & 68.6 \\
\hline $81-89$ & 24 & 22.9 \\
\hline$\leq 90$ & 9 & 8.9 \\
\hline
\end{tabular}

Table V Correlation between achieving target systolic blood pressure level and some selected variables (univariate analysis)

\begin{tabular}{lcc}
\hline Correlation traits & r-value & P-value \\
\hline Age of patient in years & 0.437 & $0.001^{\mathrm{S}}$ \\
Duration of diabetes in years & 0.204 & $0.025^{\mathrm{S}}$ \\
Duration of hypertension in years & 0.131 & $0.047^{\mathrm{S}}$ \\
Number of medication & 0.634 & $0.051^{\mathrm{NS}}$ \\
\hline
\end{tabular}


Table VI Correlation between achieving target diastolic blood pressure level and some selected variables (univariate analysis)

\begin{tabular}{lcc}
\hline Correlation traits & r-value & P-value \\
\hline Age of patient in years & 0.854 & $0.019^{\mathrm{S}}$ \\
Duration of diabetes in years & 0.574 & $0.031^{\mathrm{S}}$ \\
Duration of hypertension in years & 0.385 & $0.020^{\mathrm{S}}$ \\
Number of medication & 0.174 & $0.014^{\mathrm{S}}$ \\
\hline
\end{tabular}

$\mathrm{r}=$ Correlation coefficient

$\mathrm{S}=$ significant

$\mathrm{NS}=$ not significant

$P$ value reached from $t-$ test

\section{DISCUSSION}

The natural history of CKD is characterized by hypertension, along with increasing albuminuria and decreasing GFR. In both type 1 and type 2 diabetes, the natural history is similar, with the exception that onset of hypertension and vascular disease is earlier in the course of kidney disease in type 2 diabetes. ${ }^{20-23}$ A large number of epidemiological studies and controlled trials have defined hypertension as a risk factor for progression of $\mathrm{DKD}$, and antihypertensive treatment reduces this risk.

CKD was determined by duration of kidney disease, serum creatinine and eGFR (Cockcroft and Gault equation). The mean age was 55.67 years their age ranged from 39 to 66 years. Among 105 subjects 52.38\% were male and rest $47.62 \%$ were female. This present study findings are very much comparable with the described epidemiology ${ }^{20}$ of diabetic CKD patients.

The study revealed that IHD (30.48\%), dyslipidaemia (56.19\%) and stroke (13.33\%) were associated with CKD. Previous studies revealed most common association of CKD are diabetes mellitus, hypertension, and glomerulonephritis approximately in $75 \%$ of all adult cases. ${ }^{24-27}$ Association of IHD, dyslipidaemia was also reported in $60 \%$ of CKD cases. ${ }^{30-33}$ The present study findings were comparable with the previous study.

The eGFR (mean) was $52.19 \mathrm{ml} / \mathrm{min}$ and standard deviation of mean was (SD) $\pm 27.13 \mathrm{ml} / \mathrm{min}$ in this present study. The eGFR ranged from 14.3 to $66.94 \mathrm{ml} / \mathrm{min}$ in the study subjects. Mean serum creatinine level was 3.4 $\mathrm{mg} / \mathrm{dl}$ with standard deviation of mean (SD) $\pm 2.26 \mathrm{mg} / \mathrm{dl}$ and the serum creatinine level ranged from 1.8 to 7.89 $\mathrm{mg} / \mathrm{dl}$ in the study subjects. Serum urea (mean $\pm \mathrm{SD}$ ) level was $88.28 \pm 29.33 \mathrm{mg} / \mathrm{dl}$. The range of serum urea was $45.99-120.31 \mathrm{mg} / \mathrm{dl}$. This ranges of serum creatinine, serum urea and eGFR was consistent with the previous studies. $^{22,24,27}$

For control of hypertension, it was observed that majority $(49.52 \%)$ on the study subjects were prescribed at least two medications to control hypertension. Three medications were given in $35.23 \%$ subjects. Only $5.73 \%$ subjects were having more than three drugs. Previous studies reported that generally, one drug (specially angiotensin converting enzyme inhibitors (ACEIs) or angiotensin II receptor antagonists (ARBs) was used in hypertensive CKD patients, as they have been found to slow the progression of CKD to stage $5 .^{30}$ However recent studies revealed that diabetic kidney disease (DKD) patients frequently required three to four medications to achieve blood pressure goals. ${ }^{30-33}$

Control of hypertension is one of the crucial factors in management of diabetic CKD patient. Apart from controlling diabetes, the goal of therapy is to slow down or halt the progression of CKD to stage 5. Control of blood pressure and treatment of the original disease, whenever feasible, are the broad principles of management. It was reported that lowering blood pressure at a level $<140 / 90 \mathrm{~mm}$ of $\mathrm{Hg}$ might halt the progression of cardiovascular morbidity but in diabetic CKD patient the recent guidelines now recommend a BP goal of $<130 / 80 \mathrm{mmHg}$ as this blood pressure level could decrease the fall of GFR rate in CKD.

In this present study, only $40 \%$ subjects achieved targeted systolic blood pressure level and $68.57 \%$ reached the targeted diastolic pressure level for CKD with diabetes. Previous studies $20,25,21$ only reported overall blood pressure control in $26.7 \%, 50 \%, 43.87 \%$, $33.9 \%$ study subjects but could not categorize systolic or diastolic blood pressure control at target level. This present study revealed that diastolic blood pressure was more controllable than systolic pressure at target level in diabetic CKD patient. These findings should be considered by the nephrologists during the treatment course in diabetic CKD patient. It was also revealed that both systolic and diastolic blood pressure (targeted) was significantly correlated with age of the subject and duration of disease. From the present study it was seen that both the targeted systolic and diastolic blood pressure was correlated with number of medication used for controlling hypertension but only diastolic blood 
pressure control was significantly correlated with number of medication used in this present study.

\section{Conclusion}

In this study it was observed that $25.72 \%$ were found to have high systolic blood pressure and $8.85 \%$ high diastolic blood pressure. It was alarming that only $40 \%$ subjects achieved targeted systolic blood pressure level and $68.57 \%$ reached the targeted diastolic blood pressure level for CKD with diabetes and both systolic and diastolic blood pressure (targeted) was significantly correlated with age of the subject and duration of disease. It denotes majority of the patient having SBP and one third of the patient having DBP were above the target level set for them. So physicians should pay attention during treatment of hypertension in diabetic CKD patients, and as majority of the patient could not achieve targeted systolic blood pressure further attention should be given in this regard.

\section{Limitations}

This was single centered study observational study with small sample size.

Authors' contribution: MSHK, ZAL planned study. MSHK drafted manuscript. All authors read and approved the final manuscript for publication.

Conflict of interest: Nothing to declare.

\section{REFERENCES}

1. Zimmet PZ, Magliano DJ, Herman WH, Shaw JE. Diabetes: a 21 st century challenge. Lancet Diabetes Endocrinol 2014;2:56-64.

2. Atlas, Diabetes. International diabetes Federation.10th edi. IDF diabetes Atlas, 2019.

3. International Centre for Diarrhoeal Disease Research, Bangladesh. Available: https://www.icddrb.org/news-andevents/press-corner/ media-resources/non-communicablediseases [Accessed 06 Sep 2019].

4. Sayeed MA, Banu A, Khan AR. Prevalence of diabetes and hypertension in a rural population of Bangladesh. Diabetes Care 1995; 18:555-8.

5. Saquib N, Khanam MA, Saquib J, Anand S, Chertow GM, Barry $M$, et al. High prevalence of type 2 diabetes among the urban middle class in Bangladesh. BMC Public Health 2013;13:1032.

6. Jha V, Garcia-Garcia G, Iseki K, Li Z, Naicker S, Plattner B, et al. Chronic kidney disease: global dimension and perspectives. Lancet 2013;382(9888): 260-72.
7. Mills KT, Xu Y, Zhang W, Bundy JD, Chen CS, Kelly TN, et al. A systematic analysis of worldwide population-based data on the global burden of chronic kidney disease in 2010. Kidney Int 2015;88(5):950-7.

8. Roy A, Praveen PA, Amarchand R, Ramakrishnan L, Gupta $\mathrm{R}$, Kondal D, et al. Changes in hypertension prevalence, awareness, treatment and control rates over 20 years in National Capital Region of India: results from a repeat cross-sectional study. BMJ Open 2017;7(7):e015639.

9. Meo SA, Zia I, Bukhari IA, Arain SA. Type 2 diabetes mellitus in Pakistan: current prevalence and future forecast. J Pak Med Assoc 2016;66(12):1637 -42.

10. Mendis S, Puska P, Norrving B. World Health Organization. Global atlas on cardiovascular disease prevention and control. Geneva: WHO; 2011.

11. Sarki AM, Nduka CU, Stranges S, Kandala NB, Uthman OA. Prevalence of Hypertension in Low- and MiddleIncome Countries: A Systematic Review and MetaAnalysis. Medicine (Baltimore) 2015;94(50):e1959.

12. Kearney PM, Whelton M, Reynolds K, Muntner P, Whelton PK, He J. Global burden of hypertension: analysis of worldwide data. Lancet 2005;365:217-23.

13. Chowdhury MZI, Rahman M, Akter T, Akhter T, Ahmed A, Shovon MA, et al. Hypertension prevalence and its trend in Bangladesh: evidence from a systematic review and meta-analysis. Clinical Hypertension. BioMed Central; 2020;26:10.

14. Bidani AK, Griffin KA. Pathophysiology of hypertensive renal damage: implications for therapy. Hypertension. 2004;44:595-601.

15. Gansevoort RT, Correa-Rotter R, Hemmelgarn BR, Jafar TH, Heerspink HJ, Mann JF, et al. Chronic kidney disease and cardiovascular risk: epidemiology, mechanisms, and prevention. Lancet. 2013;382:339-52.

16. Cheung AK, Rahman M, Reboussin DM, Craven TE, Greene T, Kimmel PL, et al. Effects of intensive BP control in CKD. J Am SocNephrol. 2017;28:2812-23.

17. Sayeed MA, Banu A, Haq JA, Khanam PA, Mahtab H, Azad Khan AK. Prevalence of hypertension in Bangladesh: effect of socioeconomic risk factor on difference between rural and urban community. Bangladesh Med Res Counc Bull 2002;28:7-18.

18. Damasceno A, Azevedo A, Silva-Matos C, Prista A, Diogo D, Lunet N. Hypertension prevalence, awareness, treatment, and control in mozambique: urban/rural gap during epidemiological transition. Hypertension 2009;54:77-83.

19. Hashmi SK, Afridi MB, Abbas K, Sajwani RA, Saleheen D, Frossard PM, et al. Factors associated with adherence to anti-hypertensive treatment in Pakistan. PLoS ONE 2007;2:e280. 
20. Hsu CY, McCulloch CE, Darbinian J, Go AS, Iribarren C. Elevated blood pressure and risk of end-stage renal disease in subjects without baseline kidney disease. Arch Intern Med. 2005; 165: 923-8.

21. Martin G Myers. Kaplan's Clinical Hypertension, 9th edn (2005). Can J Cardiol. 2007; 23(7):605.

22. MacKay JH, Areuri KE, Goldberg AI, SnapinnSM, Sweet CS. Losartan and low-dose hydrochlorthiazide in patients with essential hypertension: a double blind, placebo controlled trial of concomitant administration compared with individual components. Arch Intrn Med 1996; 156:278-345.

23. Ruilope LM, Simpson RL, Arcuri KE, Goldberg AL, Sweet CS. Controlled trial of losartan gives concomitantly with different doses of hydrochlorthiazide in hypertensive patients. Blood Press 1996; 5:32-40.

24. Hirschberg R, Wang S. Proteinuria and growth factors in the development of tubulointerstitial injury and scarring in kidney disease. CurrOpinNephrolHypertens2005; 14: 43-52.

25. Sarnak MJ, Greene T, Wang X, Beck G, Kusek JW, Collins AJ, et al. The effect of a lower target blood pressure on the progression of kidney disease: long-term follow-up of the modification of diet in renal disease study. Ann Intern Med 2005;142: 342-51.

26. Chobanian AV, Bakris GL, Black HR, Cushman WC, Green LA, Izzo JL et al. The seventh report of the Joint National Committee on prevention, detection, evaluation, and treatment of high blood pressure: the JNC 7 report. JAMA 2003;289: 2560-71.

27. European Society of Hypertension-European Society of Cardiology Guidelines Committee. 2003 European Society of Hypertension-European Society of Cardiology guidelines for the management of arterial hypertension.J. Hypertens 2003;21:1011-53.

28. ESCAPE Trial Group; Wühl E et al. Strict blood pressure control and renal failure progression in children. $\mathrm{N}$ Engl J Med 2009;361:1639-50.

29. Ruggenenti P, Perna A, Remuzzi G. Retarding progression of chronic renal disease: the neglected issue of residual proteinuria. Kidney Int2003;63:2254-61.

30. Vasan RS, Larson MG, Leip EP, Evans JC, O'Donnell CJ, Kannel WB, et al. Impact of high-normal blood pressure on the risk of cardiovascular disease. N Engl J Med 2001; 345: 1291-7.

31. Stamler J, Stamler R, Neaton JD. Blood pressure, systolic and diastolic, and cardiovascular risks.US population data. Arch Intern Med 1993; 153: 598-615.

32. Rao MV, Qiu Y, Wang C, Bakris G. Hypertension and CKD: Kidney Early Evaluation Program (KEEP) and National Health and Nutrition Examination Survey (NHANES), 1999-2004. Am J Kidney Dis 2008; 51: S30S37.

33. Cutler JA, Sorlie PD, Wolz M, Thom T, Fields LE, Roccella EJ. Trends in hypertension prevalence, awareness, treatment, and control rates in United States adults between 1988-1994 and 1999-2004. Hypertension 2008; 52: $818-27$. 